\title{
Hysteroscopy in one hundred cases of postmenopausal uterine bleeding, in the detection of uterine cancer and atypical endometrial hyperplasia
}

\author{
Pratibha Devabhaktuni $^{1 *}$, Padmaja Allani ${ }^{1}$, Suneetha Komatlapalli², \\ Rekha Rani Ksheerasagara ${ }^{1}$
}

\begin{abstract}
${ }^{1}$ Department of Obstetrics and Gynecology, Modern Government Maternity Hospital, Osmania Medical College, Hyderabad, Telangana, India

${ }^{2}$ Department of Obstetrics and Gynecology, Care Institute of Medical Sciences, Hyderabad, Telangana, India
\end{abstract}

Received: 02 May 2020

Accepted: 12 May 2020

\section{*Correspondence:}

Dr. Pratibha Devabhaktuni,

E-mail:dpdnk@yahoo.com

Copyright: () the author(s), publisher and licensee Medip Academy. This is an open-access article distributed under the terms of the Creative Commons Attribution Non-Commercial License, which permits unrestricted non-commercial use, distribution, and reproduction in any medium, provided the original work is properly cited.

\section{ABSTRACT}

Background: Evaluation was done in 100 women presenting with postmenopausal bleeding, (PMB), to discuss the utility of hysteroscopy combined guided endometrial curettage in the diagnosis of uterine cancer and endometrial hyperplasia, and, treat benign lesions, like polyps, synechiae at the same sitting. At MGMH during the years, 2002 to 2006, there were 57 women, and at care, 40 women with PMB during 2011 to 2013, and three in a nursing home, Hyderabad, were investigated.

Methods: Evaluation was done in 100 women presenting with PMB by hysteroscopy and curettage to diagnose the cause of PMB and benign lesions like polyps, synechiae were managed by operative hysteroscopy. Bettocchi $5 \mathrm{~mm}$ hysteroscope, monopolar instruments and glycine was used for excision of polyps.

Results: In one hundred women with PMB, 19\% had cancer. Endometrial adenocarcinoma in 14, endocervical carcinoma in 2, uterine carcinosarcoma in 3 cases. All 3 cases of uterine carcinosarcoma on hysteroscopy were large polyps measuring $5 \times 5-6 \mathrm{~cm}$ size. Atypical hyperplasia endometrium in $7 \%$ and simple hyperplasia in $17 \%$, was reported on histopathology, in cases with hyperplastic endometrium on hysteroscopy. Benign polyps in $41 \%$ were managed at the same sitting by operative hysteroscopy.

Conclusions: Women with postmenopausal bleeding must have USG, trans vaginal sonography (TVS), endometrial thickness (ET) measurement, preferably endometrial echo complex (EEC). In women with PMB, the risk of uterine cancer would be $19 \%$, i.e., 1 out of 5 women. Atypical hyperplasia in $7 \%$. Hysteroscopy guided curettage, with histopathology, is the gold standard protocol in cases of PMB.

Keywords: Endometrial cancer, Endometrial curettage, Endometrial hyperplasia, Hysteroscopy, Post-menopausal bleeding, Uterine carcino-sarcoma

\section{INTRODUCTION}

Postmenopausal bleeding (PMB), defined as uterine bleeding occurring after at least 1 year of amenorrhoea. WHO defines menopause as permanent cessation of menstruation resulting from loss of ovarian activity. ${ }^{1}$

The aim of investigating a woman presenting with PMB is to identify endometrial pathology, most notably to exclude endometrial carcinoma, also detect premalignant lesions, so that early treatment would help to improve the quality of life.

When should a woman be investigated if she presents with postmenopausal bleeding?

Timmermans et al, suggested that a threshold of $5 \mathrm{~mm}$ for the endometrial echo complex (EEC) would have 
sensitivity for endometrial cancer of only $90 \%$; $4 \mathrm{~mm}$, a sensitivity of $95 \%$; and $3 \mathrm{~mm}$, a sensitivity of $98 \%$. $^{2}$

Discussing about, investigating postmenopausal bleeding for endometrial cancer: cost-effectiveness of initial diagnostic strategies, Clark $\mathrm{T}$ et al, mention that the potentially most cost-effective strategies were those based on initial investigation with USS (4 and $5 \mathrm{~mm}$ ) or EB alone. ${ }^{3}$ This is from UK where NHS is available and guidelines are followed.

In India the protocols would vary based on the availability of resources, medical as well as monetary and trained medical personnel.

\section{What is the role of office-based sampling of the endometrium?}

Office-based sampling of the endometrium is associated with a procedure failure rate of approximately $10 \%$ and a tissue yield failure rate that is approximately also $10 \%{ }^{4-6}$

\section{Outpatient hysteroscopy}

In a systematic review of over 26,000 cases found that failures in the outpatient hysteroscopy ( $4.2 \%$ of the total) were attributed to either technical problems (cervical stenosis, anatomical factors and structural abnormalities) or patient factors (pain, vasovagal episodes or intolerance). ${ }^{7}$ YI Liang reported, that six cases (13\%) experienced vasovagal attacks immediately after the office vaginoscopic hysteroscopy procedure. ${ }^{8}$ The causes of the 7 cases $(16 \%)$ of incomplete examination of hysteroscopy included: blood blurred cavity 2 , nulliparity 1 , previous caesarean section 1 , longer postmenopausal years. ${ }^{8}$ Cicinelli et al, reported vasovagal attacks occurring in up to $32.5 \%$ and suggested intrauterine instillation of $2 \mathrm{ml}$ of $2 \%$ mepivacaine before performing the procedures. ${ }^{9}$

Tripodi et al, have mentioned about the importance of office hysteroscopy screening to diagnose endometrial carcinoma in menopausal women. ${ }^{10}$

Since these procedures are done without anaesthesia, varying degrees of pain experienced by women are reported. Especially elderly women post menopause, are inhibited to even have a gynaec check-up, they usually do not accept the lithotomy position and do not tolerate well office endometrial biopsy sampling. There are some side effects mentioned.

When a woman presents with postmenopausal vaginal bleeding should authors investigate if the endometrial echo complex (EEC) is less than $4 \mathrm{~mm}$ ? The answer seems to be yes as per ref. ${ }^{11,12}$

Among 250 patients with postmenopausal endometrial carcinoma (EC), 156 had type 1 EC while 94 had type 2 EC. Thirty six percent of the cohort had an EEC $\leq 4 \mathrm{~mm}$, including $37 \%$ of patients with type $1 \mathrm{EC}$ and $34 \%$ of type $2 \mathrm{EC}(\mathrm{p}=0.63)$. These results indicate that a sizable proportion of women with EC have EECs $\leq 4 \mathrm{~mm}$ during their initial evaluation. An EEC of $\leq 4 \mathrm{~mm}$ does not completely rule out endometrial cancer and cannot supplant histo pathologic evaluation (HPE). ${ }^{11}$

When limited to patients with postmenopausal bleeding, $0.9 \%$ with type $1 \mathrm{EC}$ and $25 \%$ with type $2 \mathrm{EC}$ had an EEC $\leq 4 \mathrm{~mm}(\mathrm{p}<0.001)$, concluded that a thin endometrial stripe, especially when associated with postmenopausal vaginal bleeding does not reliably exclude type $2 \mathrm{EC}$ and tissue HPE is recommended. ${ }^{12}$

Individual patient characteristics including age, time since menopause, obesity, hypertension, and diabetes mellitus are known risk factors for endometrial carcinoma. The incidence of cancer is higher in women with PMB and obesity (18\%) or with PMB and diabetes $(21 \%)$. In obese women with diabetes the incidence may be as high as $29 \% .{ }^{13,14}$ Endometrial cancer in women with PMB is $\sim 10 \%$, which rises from $1 \%$ in women aged $<50$ years to almost $25 \%$ in women during the eighth decade of life. Women receiving tamoxifen experience a three- to six-fold greater incidence of endometrial cancer due to its weak estrogenic effect on the endometrium. Treatment beyond 5 years increases risk by at least four-fold. ${ }^{15-17}$

Most cases of endometrial cancer present with abnormal uterine bleeding, but no bleeding is present in approximately $5-20 \%$ of cases. ${ }^{18,19}$ These asymptomatic postmenopausal women may be detected during routine health examinations, when on ultrasonography they may have endometrial thickness (ET) more than $4 \mathrm{~mm} \mathrm{-} 5$ $\mathrm{mm}$.

Women coming for health check up in the postmenopausal period, authors have advised routinely,

- Examination of the breast by the gynaecologist, USG and mammography if the patient can afford, definitely if there is positive family history.

- Cervical smear for Pap. testing and HPV DNA cervical smear testing, if they can afford,

- Whole abdomen ultrasonography including Trans vaginal scan, especially for endometrial thickness, endometrial echo complex (EEC) measurement and ovarian size. All these in addition to blood tests as the age dictates. This is the protocol authors have been following since ten years. This enables us to diagnose breast, cervical, uterine and ovarian malignancies at an early stage.

In this context authors have come across women having ET $>5 \mathrm{~mm}$ reported on USG without their having any PMB. Authors went ahead with hysteroscopy and endometrial curettage in them. ${ }^{20}$

In women presenting with $\mathrm{PMB}$, having ET $>5 \mathrm{~mm}$ reported on USG, authors have performed hysteroscopy 
combined endometrial curettage in one hundred women as prospective study, during 2002 to 2006, and again 2011 to 2013 , at two different institutes.

This is consistent with guidelines from the Society of gynecologic oncologists that advises that when hysteroscopy is used, biopsy should be performed of any discrete lesions as well as of the random background endometrium. $^{21}$

In patients with atypical endometrial hyperplasia, the detection of endometrial cancer before hysterectomy can decrease the risk of suboptimal treatment. ${ }^{22}$ Of the 26 patients who had been diagnosed with atypical endometrial hyperplasia by office based endometrial biopsy, eight $(30.8 \%)$ were subsequently diagnosed with endometrial cancer after they had undergone hysterectomy. ${ }^{22}$

\section{METHODS}

Evaluation was done in 100 women presenting with PMB by hysteroscopy and curettage to diagnose the cause of $\mathrm{PMB}$ and benign lesions like polyps, synechiae were managed by operative hysteroscopy.

Bettocchi $5 \mathrm{~mm}$ hysteroscope, monopolar instruments and glycine was used for excision of polyps.

At MGMH during the years, 2002 to 2006, there were 57 women, and at CARE, 40 women with PMB during 2011 to 2013 , and three in a private nursing home, Hyderabad, were investigated.

\section{Inclusion criteria}

- $\quad$ PMB after 1 year of menopause

- Endometrial thickness with $>5 \mathrm{~mm}$ on USG, trans vaginal sonography (TVS)

- Family history of Ca endometrium

- Recurrent postmenopausal bleeding

- Women with hypothyroidism

- Women on HRT, anticoagulants and antiplatelets use.

\section{Exclusion criteria}

- Pre-menopausal women

- Post hysterectomy women

- Cervical and vaginal lesions

- Cervical cancer

- Vulval and vaginal cancer

- Trauma to genital tract.

An informed consent was obtained and full assessment done by history (complete medical history), physical examination was conducted and relevant laboratory investigations were carried out, which include compete blood picture, fasting blood sugar, serum TSH, pap smear and pelvic ultrasound (transvaginal ultrasound with Doppler).

Government maternity hospital (MGMH) hysteroscopy was performed in 400 women for various gynaecological conditions, from February 2002 to December 2006 at MGMH. Out of 400, postmenopausal bleeding was the reason for hysteroscopy in 57 women.

A prospective analytical study was conducted at Care institute of medical sciences, Hyderabad, Andhra Pradesh between August 2011 to December 2013 in collaboration with department of radiology and pathology.

The protocol for the study was approved by the ethics committee of the hospital.

A total of 60 postmenopausal women, out of which 40 presented clinically with post-menopausal bleeding and 20 presented with increased endometrial thickness on routine USG without bleeding.

Preoperative surgical profile investigations were performed as per protocol. Hysteroscopy and endometrial curettage was performed under general anaesthesia and the biopsy/curetting's were sent for histopathological evaluation. The slides were reviewed and classified using current pathologic criteria.

\section{RESULTS}

Findings observed on hysteroscopy: were, atrophic endometrium in 13, proliferative endometrium in 6 , hyperplastic endometrium in 24 , (simple hyperplasia and cystic hyperplasia in 17 and hyperplasia with atypia in 7), benign endometrial polyps in 41 , benign endocervical polyps in 3, uterine cancer - polypoidal growth in 19, IUCD in 2, submucous Fibroid in 3 , synechiae in 4 (Table 1). Some of study observed findings are shown in (Figures, 1-10).

Table 1: Observations on hysteroscopy in 100 cases of postmenopausal uterine bleeding.

\begin{tabular}{|l|ll|}
\hline Hysteroscopy findings & Number & $\%$ \\
\hline Atrophic endometrium & 13 & $13 \%$ \\
\hline Normal-proliferative endometrium & 6 & $6 \%$ \\
\hline Hyperplastic endometrium & 24 & $24 \%$ \\
\hline Benign endometrial polyps & 41 & $41 \%$ \\
\hline Benign endocervical polyps - & 3 & $3 \%$ \\
\hline Uterine cancer - polypoidal growth & 19 & $19 \%$ \\
\hline IUCD & 2 & $2 \%$ \\
\hline Submucous fibroid & 3 & $3 \%$ \\
\hline Synechiae & 4 & $4 \%$ \\
\hline
\end{tabular}

In one hundred women with PMB, 19\% had cancer. Endometrial adenocarcinoma in 14, endocervical carcinoma in 2, uterine sarcoma in 3 cases. All 3 cases of uterine sarcoma on hysteroscopy were large polyps 
measuring $5 \times 7 \quad \mathrm{~cm}$ size. Atypical hyperplasia endometrium in $7 \%$ and simple hyperplasia in $17 \%$, was reported on histopathology, in cases with hyperplastic endometrium on hysteroscopy. Benign polyps in $41 \%$ were managed at the same sitting (Table 2).

For a case of postmenopausal bleeding who had PMB since 11 months on and off, TVS showed at endometrial thickness of $9.2 \mathrm{~mm}$ with no polyp reported. But on hysteroscopy a large polyp, $3.5 \times 15 \mathrm{~cm}$ was seen. Some times the scan may not be accurate in detecting endometrial polyp. Hence hysteroscopy is the gold standard in the diagnosis and management of PMB.

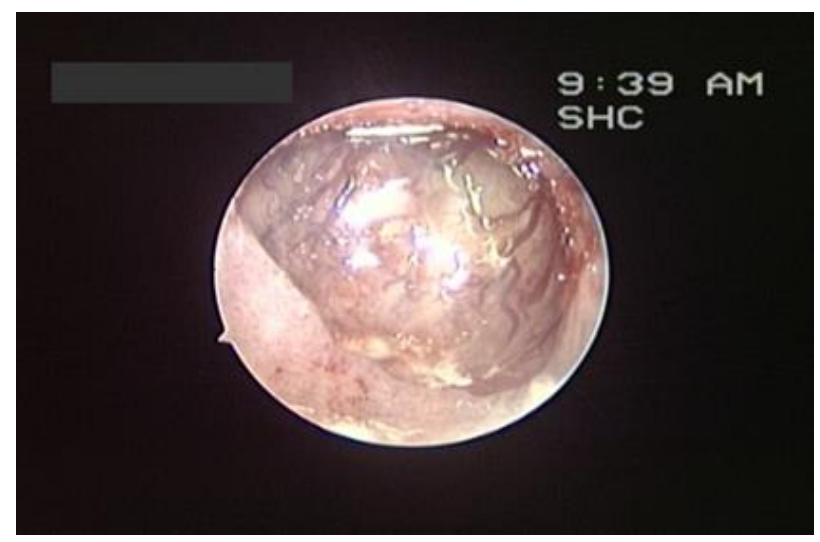

Figure 1: Long polyp on hysteroscopy.

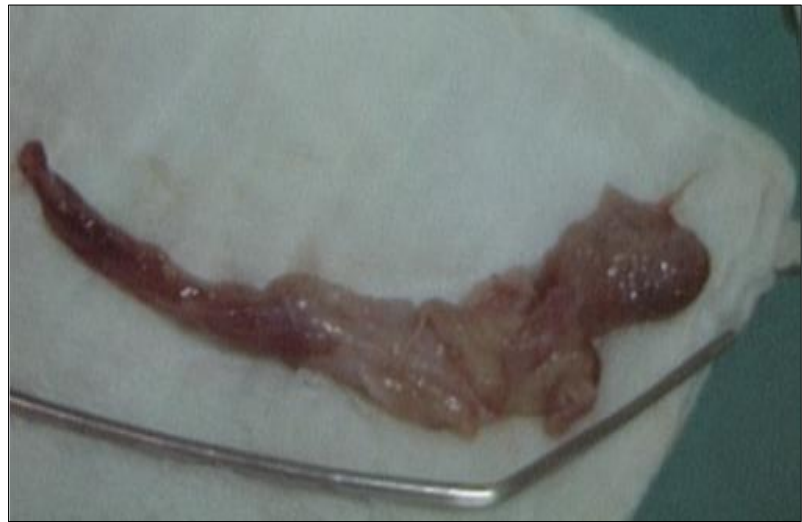

Figure 2: Long polyp of size $3.5 \times 15 \mathrm{~cm}$.

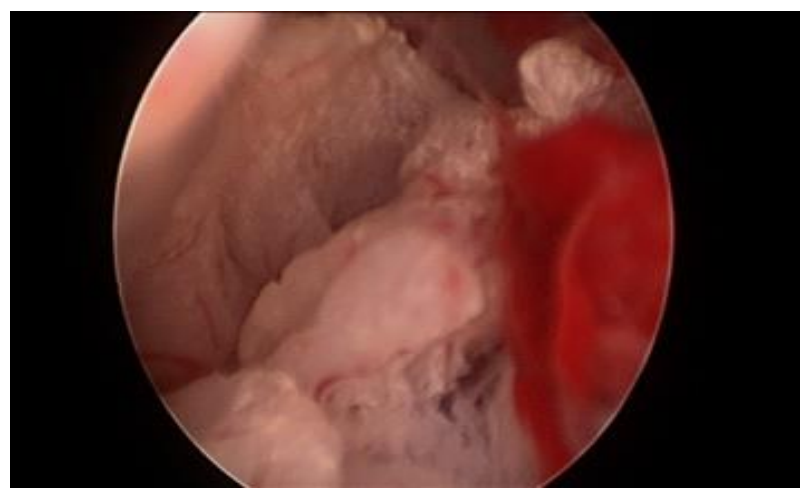

Figure 3: Endometrial cancer.

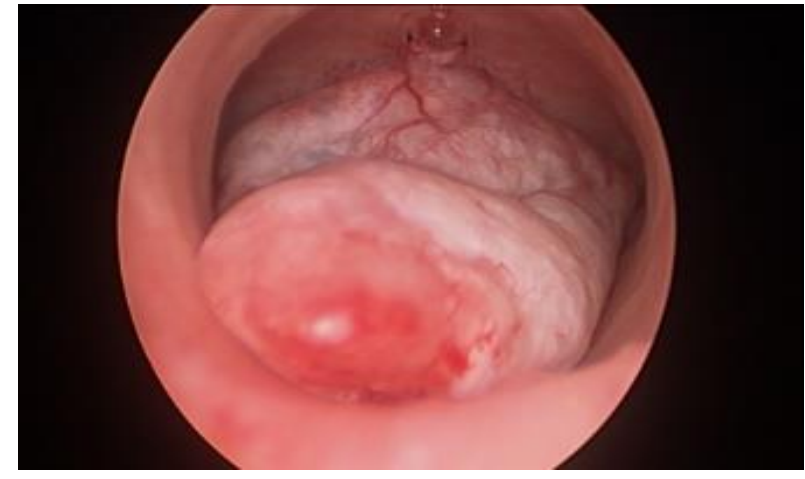

Figure 4: Benign polyp in PMB.

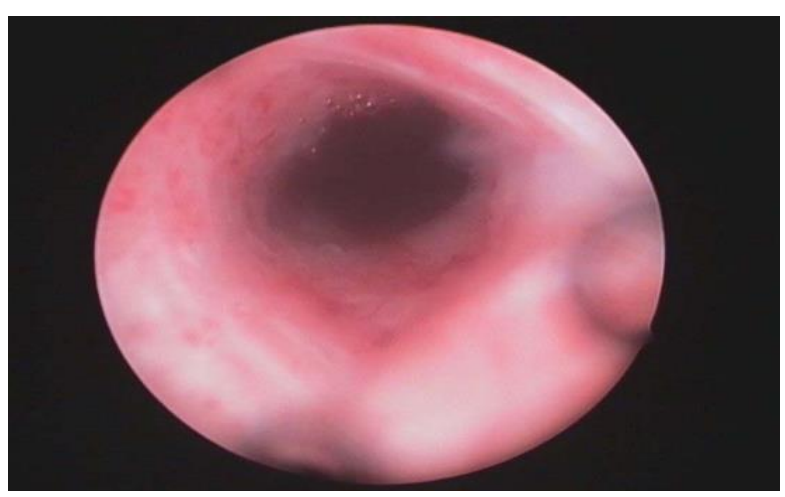

Figure 5: Visualising the endocervical canal to exclude lesions.

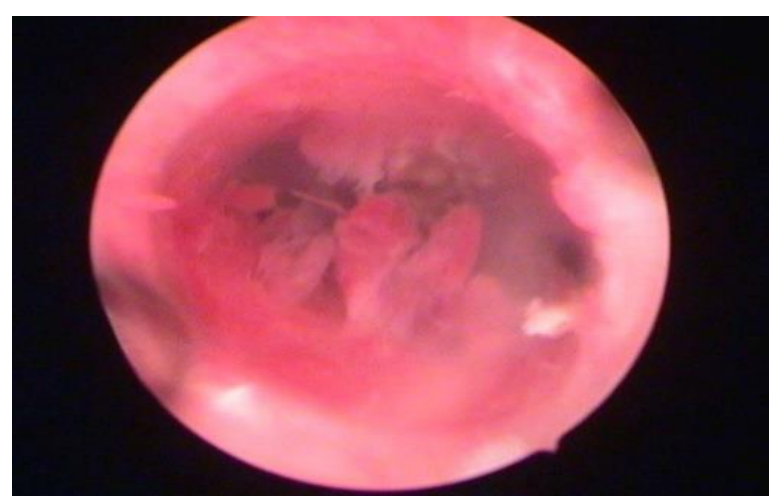

Figure 6: Endometrial hyperplasia in PMB.

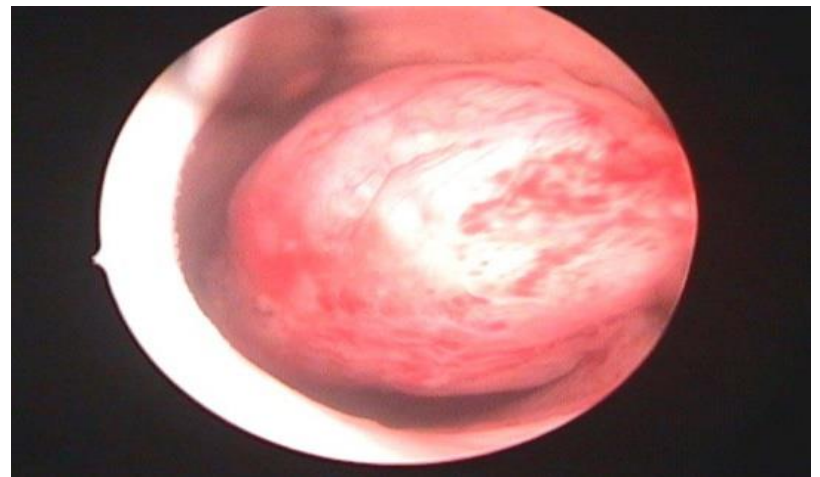

Figure 7: Endometrial polyp from left lateral uterine wall. 


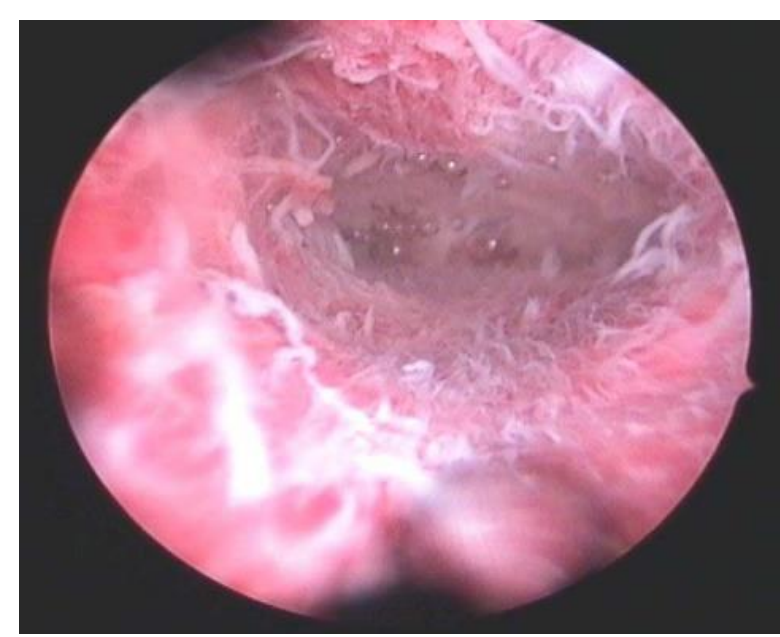

Figure 8: Panoramic view after endometrial curettage.

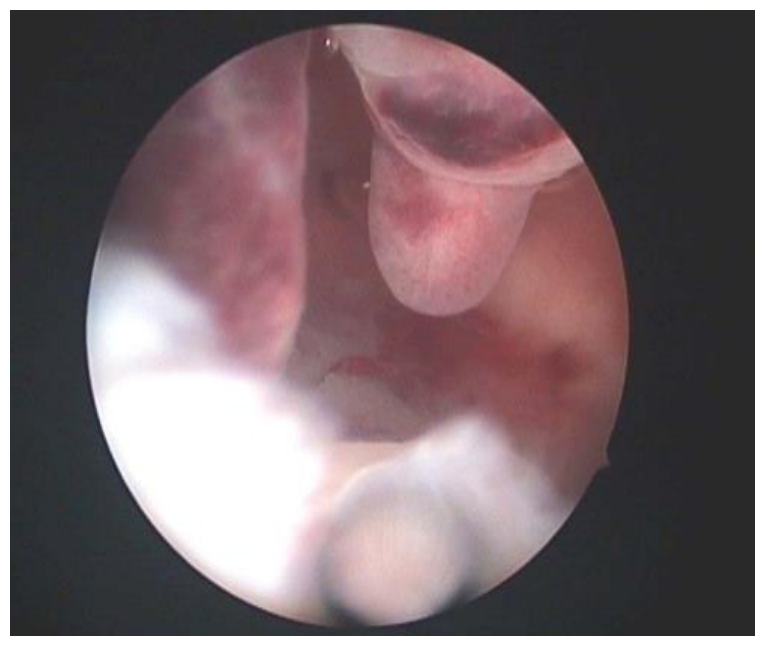

Figure 9: Benign endometrial polyps in PMB.

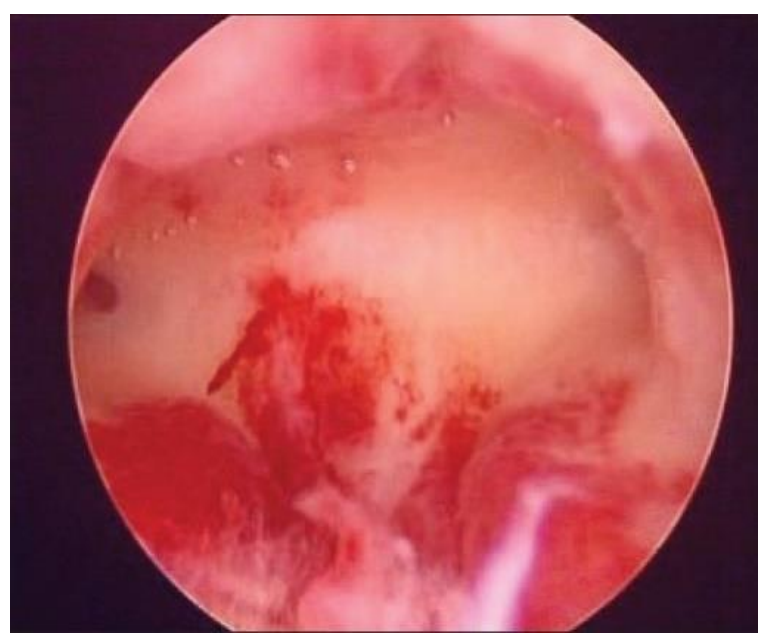

Figure 10: Broken synechiae in PMB.

In this study endo. cancer among PMB, 19\%, and atypical hyperplasia - $7 \%$. Only $74 \%$ due to benign causes.
It is significant to note that $51 \%$ of women had presented with PMB in the sixth decade of life (50-59 years). In the seventh decade $21 \%$ and $8 \%$ in the eighth decade (Table 3).

Observations on hysteroscopy in 57 cases of postmenopausal uterine bleeding - MGMH 2002-2006, are shown in (Table 4).

Correlation between co-morbid conditions and $\mathrm{Ca}$ endometrium. Cases with PMB, N=40, CARE, are shown in (Table 5).

In this study in the PMB group $(\mathrm{N}=40)$ from Care institute, out of all co-morbidities hypertension (HTN) was associated in $70 \%$, DM in $(37.5 \%)$ hypothyroidism in $(17.5 \%)$, and obesity in $(27.5 \%)$ women. ${ }^{20} \mathrm{HTN}$ and DM (2 risk factors) were seen in $35 \%$ and three risk factors (HTN + DM + hypothyroidism) were seen in $7.5 \%$ of women.

Table 2: Histopathology of the endometrium in 100 cases of postmenopausal bleeding.

\begin{tabular}{|lll|}
\hline Hysteroscopy and histopathology & Number & $\%$ \\
\hline Atrophic endometrium & 13 & $13 \%$ \\
\hline Normal-proliferative endometrium & 6 & $6 \%$ \\
\hline $\begin{array}{l}\text { Simple hyperplasia and cystic } \\
\text { hyperplasia }\end{array}$ & 17 & $17 \%$ \\
\hline Hyperplasia with atypia & 7 & $7 \%$ \\
\hline Benign endometrial polyps & 41 & $41 \%$ \\
\hline Benign endocervical polyps & 3 & $3 \%$ \\
\hline Uterine cancer - polypoidal growth & 19 & $19 \%$ \\
\hline a Endometrial adenocarcinoma & 14 & $14 \%$ \\
\hline b Endocervical carcinoma - & 2 & $2 \%$ \\
\hline c $\quad \begin{array}{l}\text { Uterine sarcoma -large } \\
\text { polypoidal growths }\end{array}$ & 3 & $3 \%$ \\
\hline
\end{tabular}

Table 3: Age distribution of women with postmenopausal bleeding $\mathrm{N}=100$.

\begin{tabular}{|lll|}
\hline Age (years) & $\begin{array}{l}\text { Number of women with } \\
\text { PMB, } \mathbf{n = 1 0 0}\end{array}$ & $\%$ \\
\hline $45-49$ & 20 & $20 \%$ \\
\hline $50-59$ & 51 & $51 \%$ \\
\hline $60-69$ & 21 & $21 \%$ \\
\hline $70-79$ & 8 & $8 \%$ \\
\hline
\end{tabular}

Table 4: Observations on hysteroscopy in 57 cases of postmenopausal uterine bleeding - MGMH 2002-2006.

\begin{tabular}{|lll|}
\hline Hysteroscopy Findings & Number & $\%$ \\
\hline Normal & 11 & $19.9 \%$ \\
\hline Benign endometrial polyps & 24 & $42.1 \%$ \\
\hline Uterine cancer - polypoidal growth & 12 & $21 \%$ \\
\hline Hyperplastic endometrium & 8 & $14 \%$ \\
\hline IUCD & 2 & $3.5 \%$ \\
\hline
\end{tabular}


Table 5: Correlation between co-morbid conditions and Ca endometrium. cases with PMB, N=40, Care.

\begin{tabular}{|llll|}
\hline Co-morbid conditions & No of women with PMIB (n=40) & Percentage & Number of women with Ca endometrium \\
\hline DM & 15 & $37.5 \%$ & 3 \\
\hline HTN & 28 & $70 \%$ & 4 \\
\hline Hypothyroidism & 7 & $17.5 \%$ & 1 \\
\hline Obesity $($ BMI $>30)$ & 11 & $27.5 \%$ & 3 \\
\hline
\end{tabular}

Table 6: Correlation between endometrial thickness on TVS and post-menopausal bleeding.

\begin{tabular}{|lll|}
\hline ET on TVS & Number of women with PMB $(\mathbf{n}=\mathbf{4 0})$ & Percentage \\
\hline $3-4 \mathrm{~mm}$ & 4 & $10 \%$ \\
\hline $5-9 \mathrm{~mm}$ & 16 & $40 \%$ \\
\hline $10-14 \mathrm{~mm}$ & 14 & $35 \%$ \\
\hline $15-20 \mathrm{~mm}$ & 4 & $10 \%$ \\
\hline$>20 \mathrm{~mm}$ & 2 & $5 \%$ \\
\hline
\end{tabular}

Table 7: Endometrial thickness measured by 2D-TVS in relation to histopathology, N=40, Care.

\begin{tabular}{|lllllll|}
\multicolumn{1}{c}{ Histopathology } & Total & \multicolumn{7}{c|}{ Endometrial thickness on 2D-TVS } \\
\hline Ca endometrium & $(\mathbf{n = 4 0})$ & $\mathbf{3 - 4} \mathbf{~ m m}$ & $\mathbf{5 - 9} \mathbf{~ m m}$ & $\mathbf{1 0 - 1 4} \mathbf{~ m m}$ & $\mathbf{1 5 - 1 9} \mathbf{~ m m ~}$ & $>\mathbf{2 0} \mathbf{~ m m ~}$ \\
\hline Adenocarcinoma & 7 & - & - & - & - & - \\
\hline Carcino-sarcoma & 6 & - & 2 & 3 & 1 & - \\
\hline Complex hyperplasia with atypia & 1 & - & - & 1 & - & - \\
\hline Simple hyperplasia with atypia & 2 & - & 1 & 1 & - & - \\
\hline Simple hyperplasia & 2 & - & - & 2 & - & - \\
\hline Benign endometrial polyps & 17 & - & 5 & 10 & - & - \\
\hline Atrophic endometroium & 3 & 3 & - & - & - & - \\
\hline Proliferative endometrium & 3 & 1 & 2 & - & - & - \\
\hline Submucous fibroidpolyp /fibroid & 2 & - & - & 2 & - & - \\
\hline Shedding endometrium & 2 & - & 2 & - & - & - \\
\hline Total & & $\mathrm{n}=4$ & $\mathrm{~N}=12$ & $\mathrm{~N}=20$ & $\mathrm{~N}=1$ & 2 \\
\hline
\end{tabular}

Majority of the women who presented with PMB $(75 \%)$ had endometrial thickness between 5-14 mm (Table 6).

Endometrial thickness measured by $2 \mathrm{D}-\mathrm{TVS}$ in relation to histopathology, $\mathrm{N}=40$, Care institute of medical sciences (Table 7).

In this study endo. cancer among PMB, 19\%, and atypical hyperplasia - 7\%. Only $74 \%$ due to benign causes. Carcinosarcoma: case one and two were diagnosed in 2005-2006. The third case of carcinosarcoma was detected in 2012. Because of the rarity of carcinosarcoma, few details of the history is mentioned.

Mrs. S, 64 years, attained menopause fourteen years ago, presented with postmenopausal bleeding per vaginum of one-week duration. She had hypertension. Transvaginal scan revealed endometrial thickening of $14 \mathrm{~mm}$ and moderately echogenic space occupying lesion (SOL) measuring $5.1 \times 3.6 \times 3.0 \mathrm{~cm}$. with few calcifications, was noted centrally with peripheral normal myometrium. There was no hypervascularity.

Hysteroscopy revealed a large polypoidal lobulated mass, $6 \times 5 \mathrm{cms}$, from the fundus and anterior uterine wall. Increased vascularity was observed on the posterior uterine wall, and malignancy was suspected. Biopsy was reported as mixed mesodermal tumor. She was referred to the cancer institute for further management.

Mrs. N., 58 years, with no associated risk factors, presented with post-menopausal bleeding per vagina since two weeks. Endometrial thickness was $11 \mathrm{~mm}$, on transvaginal scan and hysteroscopy revealed a large polypoidal growth in the endometrial cavity, histopathology of tissue was reported as carcinosarcoma. She had treatment at an oncology centre.

Mrs. S., 62 years, para two, live two, twelve years postmenopausal, diabetic, complained of bleeding per vaginum, three episodes within two weeks. USG, TVS reported a polyp like mass in the endometrial cavity. 
Hysteroscopy was done and tissue was sent for histopathological examination. The large polypoidal mass on hysteroscopy was diagnosed as carcinosarcoma of the uterus on histopathology. Total abdominal hysterectomy with bilateral salpingo-oophorectomy were performed. Bilateral pelvic lymphnode sampling was done. Post operatively radiotherapy followed by three cycles of chemotherapy was given to her. After a few months she presented with left supraclavicular swelling (Virchow's lymphnode). FNAC (Biopsy) showed secondaries from a carcinoma. Immune histochemistry demonstrated positivity for Vimentin and Keratin. She had pathologic fracture neck of femur in February 2013 and expired eight months after the diagnosis of uterine sarcoma.

\section{DISCUSSION}

In the present series of one hundred women with PMB, $19 \%$ had cancer. Endometrial adenocarcinoma in 14, endocervical carcinoma in 2, uterine carcinosarcoma in 3 cases. Atypical hyperplasia of the endometrium in $7 \%$ and simple hyperplasia in $17 \%$, was reported on histopathology.

The combined use of hysteroscopy and endometrial curettage with histopathology would enable near $100 \%$ accuracy in the diagnosis of endometrial carcinoma and premalignant lesions. ${ }^{23}$

The results in this series were comparable to Jillani $\mathrm{K}$ et al, where the incidence of malignancy endometrial carcinoma was $16 \%$, premalignant lesios like adenomatous and atypical hyperplasia were seen in $14 \% .^{24}$

Tandulwadkar S reported in 2009 that the incidence of endometrial carcinoma was $13.33 \% .^{25}$

In authors earlier publication authors have reported that the most common finding on histopathology in PMB group $(\mathrm{N}=40)$ was benign polyps $(42.5 \%)$ and second was malignancy $(17.5 \%)$, premalignant lesions like hyperplasia with atypia $(7.5 \%)$, atrophic endometrium $(7.5 \%)$ and proliferative endometrium $(7.5 \%) .{ }^{20}$ Out of all malignancies in PMB group, 6 were endometroid adenocarcinoma and one was carcino- sarcoma. ${ }^{20}$

This study observations in Government Maternity Hospial during 2002 - 2006 (57 cases) were very similar to the data from Care hospital during 2011 - 2013 (40 cases)..$^{20}$

Lee YL et al, reports one rare case of endometrial carcinosarcoma $(2 \%)$ that was detected in their study of office vaginoscopic hysteroscopy and endometrial biopsy successful in 44 out of 45 (98\%), in the management for women with post-menopausal vaginal bleeding. ${ }^{8}$

Devi YS et al, reported in 295 cases of PMB, (19942010), uterine malignancies in 15 (5.08\%), and atypical hyperplasia in $6(2.03 \%)$, when hysteroscopy guided endometrial curettage was performed. ${ }^{26}$ They have reported a single case of leiomyosarcoma in their study.

In 2001 uterine cancer rate was reported as $5.26 \%$ in 95 cases of PMB. ${ }^{27}$ Endometrial cancer was detected in 8 $(13.33 \%)$ patients. $^{28}$

In one hundred women with PMB in this study, uterine carcinosarcoma was diagnosed in three cases.

Uterine carcinosarcomas (malignant mixed mesodermal tumours) are highly aggressive and have been considered as a subtype of sarcoma. In recent years evidence has suggested that most are monoclonal in origin and not true collision tumours. The sarcomatous element is considered to be derived from the carcinoma or from a stem cell that undergoes divergent differentiation. Thus, uterine carcinosarcomas are best regarded as metaplastic carcinomas. Carcinosarcoma are of epithelial origin, as shown by immunohistochemical and molecular studies. ${ }^{29}$ Therefore, uterine carcinosarcoma are counted as undifferentiated epithelial uterine carcinoma and should not be classified into the sarcoma group.

According to WHO classification, endometrial stromal tumours are divided into endometrial stromal nodules, low grade endometrial stromal sarcomas and undifferentiated endometrial sarcomas. Endometrial stromal tumours are the second most common mesenchymal tumours of the uterus. The most common smooth muscle tumour in the uterus is the benign leiomyoma, smooth muscle tumour of unknown malignant potential and leiomyosarcoma are the other smooth muscle tumours.

In this study, in the PMB group $(\mathrm{N}=40)$ from Care Institute, out of all co-morbidities hypertension (HTN) was associated in 70\%, DM in (37.5\%) hypothyroidism in $(17.5 \%)$, and obesity in $(27.5 \%)$ women. ${ }^{20} \mathrm{HTN}$ and DM ( 2 risk factors) were seen in $35 \%$ and three risk factors (HTN+ DM+ hypothyroidism) were seen in $7.5 \%$ of women. ${ }^{20}$

It is quite significant that asymptomatic postmenopausal women with endometrial thickness more than $5 \mathrm{~mm}$ in this study $(\mathrm{N}=20)$ had endometrial carcinoma in two, tubercular endometritis in one. ${ }^{20}$

Gerber et al, had reported a high proportion of abnormalities among asymptomatic patients, using a cutoff for endometrial thickening of $10 \mathrm{~mm} \cdot{ }^{30}$ In this study of asymptomatic patients, $16(13 \%)$ had endometrial cancer and 21 (17\%) had endometrial hyperplasia.

Asymptomatic endometrial thickening found on ultrasound examination in postmenopausal women often poses a clinical management dilemma. Although the prevalence of endometrial cancer is relatively low in women with no bleeding, the disease has a best outcome 
when it is found at an early stage. In asymptomatic postmenopausal women with increased ET, malignancy was seen in $10 \% .^{20}$

Patients with or without postmenopausal bleeding, an EEC of $4 \mathrm{~mm}$ and more, should be evaluated to rule out endometrial carcinoma and premalignant lesions of endometrial carcinoma. Patients with recurrent episodes of PMB, EEC <4 mm, but abnormal sonographic features (irregular endometrial echo, focal thickening, inhomogeneity of the endometrium, particulate fluid and increased vascularity on doppler) are noted, and in the high-risk group for endometrial carcinoma should also have evaluation. Centres where hysteroscopy is routinely done, the protocol followed to evaluate cases of PMB, after excluding cervical lesions on examination of the cervix and cytologic testing, had been to do diagnostic/ operative hysteroscopy and guided endometrial curettage. When proceeding with hysteroscopy, the patient would be counseled that operative interventions if necessary, would be done at the same sitting and the tissue would be sent for histopathology. This would avoid a second surgical procedure. This protocol would avoid medicolegal issues of late diagnosis or missed diagnosis. This protocol had been followed by the author from 1994 onwards.

\section{CONCLUSION}

Women presenting for the first time with $\mathrm{PMB}$, should undergo initial evaluation with USG, TVS, followed by hysteroscopy and endometrial curettage with HPE.

\section{ACKNOWLEDGMENTS}

Authors would like to thank the medical directors of both institutes for according permission to publish the data.

Funding: No funding sources

Conflict of interest: None declared

Ethical approval: The study was approved by the Institutional Ethics Committee

\section{REFERENCES}

1. Research on the menopause in the 1990s. Report of a WHO scientific group. World Health Organ Tech Rep Ser. 1996;866:1-107.

2. Timmermans A, Opmeer BC, Khan KS. Endometrial thickness measurement for detecting endometrial cancer in women with postmenopausal bleeding: a systematic review and meta-analysis. Obstet Gynecol. 2010;116(1):160-7.

3. Clark T, Barton P, Coomarasamy A, Gupta J, Khan $\mathrm{K}$. Investigating postmenopausal bleeding for endometrial cancer: cost-effectiveness of initial diagnostic strategies. BJOG. 2006;113:502-10.

4. Gordon SJ, Westgate J. The incidence and management of failed Pipelle sampling in a general outpatient clinic. Aust N Z J Obstet Gynaecol. 1999;39(1):115-8.

5. Nagele F, O'Connor H, Baskett TF, Davies A, Mohammed H, Magos AL. Hysteroscopy in women with abnormal uterine bleeding on hormone replacement therapy: a comparison with postmenopausal bleeding. Fertil Steril. 1996;65(6):1145-50.

6. Giusa-Chiferi MG, Gonçalves WJ, Baracat EC, de Albuquerque Neto LC, Bortoletto CC, de Lima GR. Transvaginal ultrasound, uterine biopsy and hysteroscopy for post-menopausal bleeding. Int $\mathbf{J}$ Gynaecol Obstet. 1996;55(1):39-44.

7. Jansen FW, Vredevoogd CB, van Ulzen K, Hermans J, Trimbos JB, Trimbos- Kemper TC. Complications of hysteroscopy: a prospective, multicenter study. Obstet Gynecol. 2000;96:266e70.

8. Lee YL, Bai YS, Yin CS. Vaginoscopic hysteroscopy in management for women with postmenopausal vaginal bleeding. Taiwan J Obstet Gynecol. 2019;58:497e500.

9. Cicinelli E, Didonna T, Ambrosi G, Schonauer LM, Fiore TG, Matteo MG. Topical anaesthesia for diagnostic hysteroscopy and endometrial biopsy in postmenopausal women: a randomised placebocontrolled double-blind study. Br J Obstetr Gynaecol March. 1997;104:316e9.

10. Tripodi A, De Salvo C, Ermio C, Manuzio D, Romeo $\mathrm{G}$, Vadalà P. Importance of office hysteroscopy screening to diagnose endometrial carcinoma in menopausal women. Eur J Gynaecol Oncol Int J. 2011;3:303-7.

11. Chandavarkar U, Kuperman J, Muderspach L. Postmenopausal endometrial cancer: evaluating the role of endometrial echo complex. Gynecol Oncol. 2011;120:S11.

12. Wang J, Wieslander C, Hansen G, Cass I, Vasilev S, Holschneider $\mathrm{CH}$. Thin endometrial echo complex on ultrasound does not reliably exclude type 2 endometrial cancers. Gynecol Oncol. 2006;101(1):120-5.

13. Van Doorn LC, Dijkhuizen FP, Kruitwagen RF, Heintz AP, Kooi GS. Accuracy of trans vaginal ultrasonography in diabetic or obese women with postmenopausal bleeding. Obstet Gynaecol. 2004;104:571-8.

14. Martinez Rubio M, Alcazar J. Ultrasonographic and pathological endometrial findings in asymptomatic postmenopausal women taking antihypertensive drugs. Maturitas. 2003;46:27-32.

15. American College of Obstetricians and Gynecologists Committee on Gynecologic Practice: Committee Opinion No. 601: Tamoxifen and uterine cancer. Obstet Gynecol. 2014;123:1394.

16. American College of Obstetricians and Gynecologists Committee on Gynecologic Practice: Tamoxifen and endometrial Cancer. Committee opinion 232. ACOG; Washington, DC.; 2000.

17. Ettinger B, Li DK, Klein R. Unexpected vaginal bleeding and associated gynecologic care in 
postmenopausal women using hormone replacement therapy: comparison of cyclic versus continuous combined schedules. Fertil Steril. 1998;69(5):865-9.

18. Scottish intercollegiate guidelines network. Investigation of Post-9. Menopausal bleeding section 5: interpretation of transvaginal ultrasound (TVUS). Edinburgh: SIGN; 2002.

19. Smith-Bindman R, Weiss E, Feldstein V. How thick is too thick? When 10. endometrial thickness should prompt biopsy in postmenopausal women without vaginal bleeding. Ultrasound Obstet Gynecol. 2004;24:558.

20. Devabhaktuni P, Suneeta K, Kancharla K. Role of hysteroscopy and endometrial curettage in postmenopausal women with and without postmenopausal bleeding. Gynecol Obstet Open Acc. 2018:OBOA-125.

21. Trimble CL, Method M, Leitao M. Management of endometrial precancers. Obstet Gynecol. 2012;120:1160.

22. Byun JM, Jeong DH, Kim YN, Cho EB, Cha JE, Sung MS, Lee KB, Kim KT. Endometrial cancer arising from atypical complex hyperplasia: The significance in an endometrial biopsy and a diagnostic challenge. Obstet Gynecol Sci. 2015;58(6):468-74.

23. Mencaglia L. Hysteroscopy and adenocarcinoma. Obstet Gynecol Clin North Am. 1995;22(3):573-9.

24. Jillani K, Khero RB, Maqsood S, Siddiqui MA. Prevalence of malignant disorders in 50 cases of postmenopausal bleeding. J Pak Med Asso. 2010;60(7):540.
25. Tandulwadkar S, Deshmukh P, Ln P. Hysteroscopy in post24. menopausal women. J Gynecol Endosc Surg. 2009;1:89-93.

26. Devi YS, Swapna KT, Naidu TK. Conservative surgical alternatives to hysterectomy, Chapter in Obstet Gynecol Update; 2011:249-295.

27. Devi YS, Swapna KT. Diagnostic and operative hysteroscopy in the management of postmenopausal bleeding. J Obst Gyn India. 2001;51(2):115-9.

28. Singh P, Dwivedi P, Mendiratta S. Correlation of endometrial thickness with the histopathological pattern of endometrium in postmenopausal bleeding. J Obstet Gynaecol India. 2016;66(1):42-6.

29. Amant F, Moerman P, Neven P, Timmerman D, Van Limbergen E, Vergote I. Endometrial Cancer. Lancet. 2005;366:491-505.

30. Gerber B, Krause A, Müller H, Reimer T, Külz T. Ultrasonographic detection of asymptomatic endometrial cancer in postmenopausal patients offers no prognostic advantage over symptomatic disease discovered by uterine bleeding. Eur $\mathrm{J}$ Cancer. 2001;37:64-71.

Cite this article as: Devabhaktuni $\mathrm{P}$, Allani $\mathrm{P}$, Komatlapalli S, Ksheerasagara RR. Hysteroscopy in one hundred cases of postmenopausal uterine bleeding, in the detection of uterine cancer and atypical endometrial hyperplasia. Int J Reprod Contracept Obstet Gynecol 2020;9:2253-61. 